\title{
Keseuaian Lahan Untuk Pengembangan Padi Varietas Ranta Dan Habo Kecamatan Batui Kabupaten Banggai
}

\author{
Hidayat A. Katili ${ }^{1 *}$ dan Nurul Mitra Sari ${ }^{2)}$ \\ 1)*,2) Program Studi Agroteknologi Fakultas Pertanian Universitas Tompotika Luwuk \\ email: hidayat.katili11@gmail.com ${ }^{1)^{*}}$,nurulmitrasari@gmail.com ${ }^{2)}$
}

\begin{abstract}
ABSTRAK
Padi (Oryza sativa L.) merupakan tanaman pangan terhadap kebutuhan utama penduduk. Sehingga perlunya implementasi lapangan yang merupakan upaya pengembangan padi lokal habo dan ranta merujuk pada pemanfaatan lahan kering dengan mengestimasi karakter dan sifat-sifat lahannya. Penelitian bertujuan menegtahui kesesuaian lahan dan faktor pembatas serta arahan pengembangan padi lokal varietas ranta dan habo di Kecamatan Batui Kabupaten Banggai. Penelitian ini menggunakan pendekatan parametrik dengan sistem klasifikasi atas dasar nilai ciri lahan dengan metode Indek Lahan Akar Kuadrat. Hasil dari penelitian ini diperoleh kelas kesesuaian lahan secara faktual tanaman padi varietas ranta dan habo di Kecamatan Batui berstatus cukup sesuai (S2) yang terletak pada satuan peta lahan (SPL) 2,5,6,7, dengan faktor pembatas kemiringan lereng, bahaya erosi, $\mathrm{N}$-total, $\mathrm{P}_{2} \mathrm{O}_{5}$ dan $\mathrm{K}_{2} \mathrm{O}$. Selain dari itu diperoleh kesesuaian lahan tergolong marginal (S3) pada satuan peta lahan 3,4,8,9 dengan faktor pembatas yaitu hara tersedia $\left(\mathrm{N}\right.$-total, $\mathrm{P}_{2} \mathrm{O}_{5}$ dan $\mathrm{K}_{2} \mathrm{O}$ ) yang tergolong rendah sampai sangat rendah. sehingga dalam upaya perbaikannya perlu dilakukan usaha yang sesuai dengan peruntukkan setiap faktor pembatas dilokasi penelitian, agar diperoleh keseuaian lahan potensial untuk tanaman padi ranta dan habo sehingga pada SPL 1,2,3,4,5,6,7,8,9 diperoleh status sangat sesuai (S1) dengan luas 25.016,4 ha. Dengan begitu, alokasi lahan komoditas tanaman padi lokal ranta dan habo dapat dikembangkan secara menyeluruh diwilayah Kecamatan Batui sesuai dengan konsep perencanaan pengembangan komoditi padi lokal ranta dan habo.
\end{abstract}

Kata kunci: Kesesuaian Lahan, Padi, Ranta, Habo

\section{PENDAHULUAN}

Tanaman padi (Oryza sativa L.) merupakan sumber tanaman pangan penting yang dijadikan sebagai makanan pokok setengah penduduk dunia (Safitri, 2018). Kebutuhan beras sebagai salah satu sumber pangan utama penduduk Indonesia terus meningkat. Seiring dengan peningkatan jumlah penduduk, maka kebutuhan beras di Negara kita semakin meningkat (Sarwanto et al, 2018), sehinggga diperlukan upaya keras dalam meningkatkan produksi beras baik secara kualitas maupun kuantitas. Agar kebutuhan yang terus meningkat dapat diimbangi.

Permasalahan yang paling menonjol yakni masyarakat Kecamatan Batui khususnya petani beranggapan bahwa tanaman padi yang dibudidayakan pada lahan kering tidak akan menghasilkan produksi yang baik karena lahannya yang tidak tepat. Pendapat ini sekedar asumsi dari petani setempat yang didapatkan pada waktu wawancara bebas untuk menggali informan terhadap pengembangan padi lokal varietas ranta dan habo. Hal ini jelas berbeda dengan pernyataan Safitri (2018), tanaman padi mempunyai kemampuan beradaptasi serta dapat dikembangkan 
hampir pada semua lingkungan dari dataran rendah sampai dataran tinggi

Malik (2017), pengembangan padi lahan kering tidak sekedar berkaitan dengan peningkatan produktivitas akan tetapi peningkatan produksi padi dalam kawasan. Maka dari itu perlunya usaha pengembangan padi ladang lokal dalam perspektif kebijakan dan implementasi yang adaptif merupakan salah satu alternatif yang diharapkan dapat meningkatkan dan menstabilkan produksi padi secara nasional (Suardi 2002; Juradi et al. 2015: Sutanto et al. 2020).

Sehingganya Upaya pengembangan padi ladang lokal merujuk pada pemanfaatan lahan kering, karena kontribusi padi lokal terhadap produksi padi nasional masih relatif rendah, sehingga pengembangannya masih terus diupayakan dengan memperhitungkan dan memanfaatkan kemampuan penggunaan lahannya. Kemampuan penggunaan lahan yaitu suatu sistematik dari persuaratan penggunaan lahan yang didasarkan dari sifat-sifatnya dalam menentukan potensi suatu lahan yang baik secara lestari. Kualitas lahan yang digunakan untuk menentukam klasifikasi kesesuaian lahan dilakukan upaya peningkatan penggunaan lahan demi memperbaiki karakteristik dan kualitas lahan yang akan ditanami (Siswanto, 2006; Rayes, 2007).

Kesesuaian suatu lahan akan berbeda beda, tergantung dari penggunaan lahan suatu kawasan yang dikehendaki. Selanjutnya Klasifikasi kecocokkan lahan barkaitan dengan perbandingan (matching) antara kualitas lahan yang dipadukan dengan persyaratan penggunaannya (FAO, 1976). Sehingganya salah satu pendekatan yang dapat dilakukan adalah mengunakan pendekatan parametrik. Menurut sehinggahnya dapat meningkatkan produktivitas padi disuatu wilayah.

Nainggolan et al, (2015) pendekatan paramertik yaitu sistem pendekatan klasifikasi dengan pembagian atas lahan atau penilaian dari ciri lahan (Mulianto et al 2020) dan kemudian mengkombinasikan pengaruh-pengaruh dari suatu lahan (Amir, 2018). Serta hasil selanjutnya akan dituangkan dalam bentuk peta sehinggahnya luaran yang dihasilkan dapat dirahkan berdasarkan kecocokan/ kesesuaian lahannya.

\section{BAHAN DAN METODE}

Penelitian ini dilakuakn sejak bulan Juli samapi September di Kecamatan Batui Kabupaten Banggai tahun 2020, yaitu penelitian lapang untuk mengambil sampel tanah berdasarkan Satuan Peta Lahan (SPL), setiap satu titik pada SPL di ambil beberapa sampel lalau di kompositkan. Pengambilan sampel tanah dengan menggunakan Bor tipe Belgia, setiap sampel tanah komposit dimasukkan kedalam kantong plastik untuk dibawah ke laboratorium dan dianalisis. Selanjutnya melakukan pengamatan warna tanah dengan menggunakan Muncel, serta melakukan pengamatan struktur tanah, batas horizon, perakaran dan mengukur kedalaman tanah yang diamati dilapangan.

Kelas Ksesuaian laha ditetapkan berdasarkan suatu nilai indeks lahan dari kualitas lahan yang diperhitungkan dengan menggunakan metode akar kuadrat (Sys et al., 1991) berikut.

$$
\begin{aligned}
& \text { I=Rmin } x=\sqrt{\frac{\mathrm{A}}{100}} \quad x \quad \frac{\mathrm{B}}{100} \quad x \quad \ldots \\
& \text { Dimana: } \\
& \text { I } \quad=\text { Indeks Lahan } \\
& \text { Rmin } \quad \text { Rating minimum kualitas lahan }
\end{aligned}
$$


$\mathrm{A}, \mathrm{B}=$ Rating kualitas lahan lainnya selain rating kualitaslahan minimum
Selanjutnya nilai indek lahan yang didapatkan akan dicocokkan dengan nilai pada Tabel 1 dibawah ini untuk menentukan kesesuaian lahananya.

Tabel 1 Kelas Kesesuaian Lahan Berdasarkan Indeks lahan

\begin{tabular}{ccc}
\hline Indeks Lahan & Kelas Kesesuaian & Lahan Keterangan \\
\hline $75-100$ & S1 & Sangat Sesuai \\
$50-75$ & S2 & Agak Sesuai \\
$25-50$ & S3 & Sesuai Marjinal \\
$0-25$ & N & Tidak Sesuai \\
\hline
\end{tabular}

Selanjutnya pengolahan data dilakukan dengan metode pembandingan antara kualitas lahan dengan persyaratan penggunaan lahan yang diinginkan (FAO 1967; Da Costa et al, 2019) yaitu karakteristik setiap lahan pada satuan peta lahan (SPL) dengan kriterian kesesuaian lahan tanaman padi lokal varietas ranta dan habo. Hasil akhir atau keluaran dari analisis ini diformulasikan dalam bentuk Peta Kesesuaian Lahan, sehingganya arahan dan tipe penggunaan lahan padi lokal ranta dan habo di Kecamatan Batui Kabupaten Banggai dapat terarah sesuai dengan sebaran wilayahnya.

\section{HASIL DAN PEMBAHASAN}

\section{Kesesuaian Lahan Aktual Padi Ranta dan Habo Kecamatan Batui}

Kualitas lahan mempunyai keragaan (performance) berpengaruh terhadap kesesuaian-nya, sesuai dengan pendugaan yang diukur secara langsung dilapangan namun secara umum ditetapkan berdasarkan karakteristik suatu lahan (FAO, 1976). Hasil kesesuaian lahan untuk tanaman padi ranta dan habo dikecamatan Batui pada SPL 1 2, 5, 6 dan 7 diperoleh hasil cukup sesuai (S2) faktor pembatasnya yaitu bahaya erosi, N-total, $\mathrm{P}_{2} \mathrm{O}_{5}$ dan $\mathrm{K}_{2} \mathrm{O}$, kemiringan lereng $(\mathrm{t})$ yang diklasifikasikan bentuk lereng cembung (Salwati dan Saidi, 2008), atau landai (Syah and Hariyanto, 2013). Selanjutnya SPL 3, 4, 8 dan 9 diperoleh status kelas kesesuaian lahan marginal (S3) yang dibatasi oleh hara tersedia ( $\mathrm{N}$-total, $\mathrm{P}_{2} \mathrm{O}_{5}$ dan $\mathrm{K}_{2} \mathrm{O}$ ) yang tergolong rendah sampai sangat rendah.

Kesesuaian lahan yang didasari dari data survey tanah atau sumberdaya lahan yang belum memperhitungkan masukka yang perlu untuk mengatasi masalah atau sebagai pembatas dari persyaratan tumbuh tanaman (Ritung et al, 2011). Selanjutnya, dlaam penentuan ksesuaian lahan juga dapat didasarkan dengan menggunakan metode parametrik FAO, (1976); Sys et al. (1991); Katili et al, (2021) dengan menjadikan beberapa indikator yang mempengaruhi karakterisrik dari suatu lahan. Adapun indikator tersebut yakni Iklim (c), kemiringan lereng (t), tingkat bahaya erosi (eh), ketersediaan air/kebahasan (w), sifat-sifat fisik tanah (s), kesuburan tanah (na) serta hara tersedia (nr). 
Usaha Perbaikan Lahan untuk Padi Ranta dan Habo Kecamatan Batui

Kesesuaian lahan yang diperoleh dilokasi penelitian berdasarkan pembobotan nilai dari setiap contoh sampel tanah tersebut didapatkan beberapa faktor penghambat dalam proses pertumbuhan dan produksi tanaman padi lokal ranta dan habo. Dengan begitu haruslah ada usaha perbaikan agar dapat meningkatkan kelas kesesuaian lahan (Nurdin et al 2011; Nganji et al, 2018; Katili, 2020). Upaya peningkatan lahan tersebut akan dilakukan estimasi dan pengamtan berdasarkan potensi kesesuaian lahan dilokasi penelitian dari sembilan sampel tanah di lokasi penelitian. Potensi yang didapatkan akan dinilai berdasarkan faktor pembatas yang dapat usahakan untuk perbaiki sebagai dasar penilaian suatu lahan seperti kemiringan lereng; Bahaya erosi; N-total, $\mathrm{P}_{2} \mathrm{O}_{5}$ serta $\mathrm{K}_{2} \mathrm{O}$ (Suryawan et al, 2020).

Ardianto dan Aliksan (2017) menyatakan panjang lereng dan kemiringan lereng akan mengakibatkan/ memberikan efek negatif pada lajunya aliran air pada permukaan tanah bagian atas serta unsure hara dari tempat sebenarnya ke tampat yang lainnya (rendah) (Wati et al, 2014). Selanjutnya Dumipto et al (2019) menyatakan bahwa, suatu kemiringan lereng yang tinggi akan menyebabkan tanah lebih mudah mengalami erosi atau kehilangan partikel tanah yang sifatnya akan merugikan petani lahan kering seperti padi ranta dan habo. Selain dari itu juga Yanti et al, (2015) menyatakan kemiringan lereng perbaikan suatu lahan akan dapat dilakukan perbaikan yaitu dengan melakukan kegiatan teknik konservasi tanah seperti melakukan pembuatan teras atau Countour Strip Cropping. Selanjutnya jika hara tersedia (N-total, $\mathrm{P}_{2} \mathrm{O}_{5} \quad$ serta $\left.\quad \mathrm{K}_{2} \mathrm{O}\right)$ tergolong rendah akan berpengaruh terhadap pertumbuhan tanaman serta rentan akan hama penyakit oleh karena itu perlu upaya perbaikan dengan pemupukan (Atmojo et al, 2018), pemberian bahan organik (Rosmaiti et al, 2019)

\section{Kesesuaian Lahan Potensial Padi Ranta dan Habo Kecamatan Batui}

Berdasarkan hasil sistem kerja kriteria Sys et al (1991) semua lahan di Kecamatan Batui dapat ditanami tanaman padi lokal ranta dan habo tetapi, dengan kelas yang berbeda serta faktor pembatas yang berbeda pula yakni, kelas S2 tehna dan S3 na, sehinggah perlunya membuat teras atau melakukan teknik penanaman sejajar kontur, dan melakukukan penanaman tanaman penutup tanah dengan pola pengolahan tinggkat sedang (Murdaningsih dan Nurdiana, 2009; Idjudin, 2011), selanjutnya perlunya usaha pengurangan laju erosi, pembuatan teras, penanaman sejajar kontur (Siregar et al 2019), penanaman tanaman penutup tanah serta perlunya melakukan penambahan pemupukan (Ritung et al, 2011).

Berdasarkan hasil pencocokan data karakteristik tanah terhadap tanaman padi lokal ranta dan habo dengan upaya perbaikan ditingkat rendah sampai sedang maka kesesuaian lahan potensial yang diperoleh pada satuan peta lahan titik 1 sampai satuan peta lahan 9 (Tabel 2) yakni tergolong sangan sesuai (S1) dengan luas 25.016,4 ha. Sehinggahnya untuk mempertahankan kemampuan kualitas tanah jangka panjang terhadap nutrisi didalamnya maka harus melakukan pemberian pupuk (organik) secara intensif dalam melakukan atau penambahan pupuk organik akan memberi pengaruh besar kearah untuk meperbaiaki kualitas sifat fisik , kimia dan biologi tanah (Margolang 
Tabel 2 Krireria Kelas Kesesuaian Lahan Tanaman Padi Lokal Ranta dan Habo di Kecamatan Batui Kabupaten Banggai.

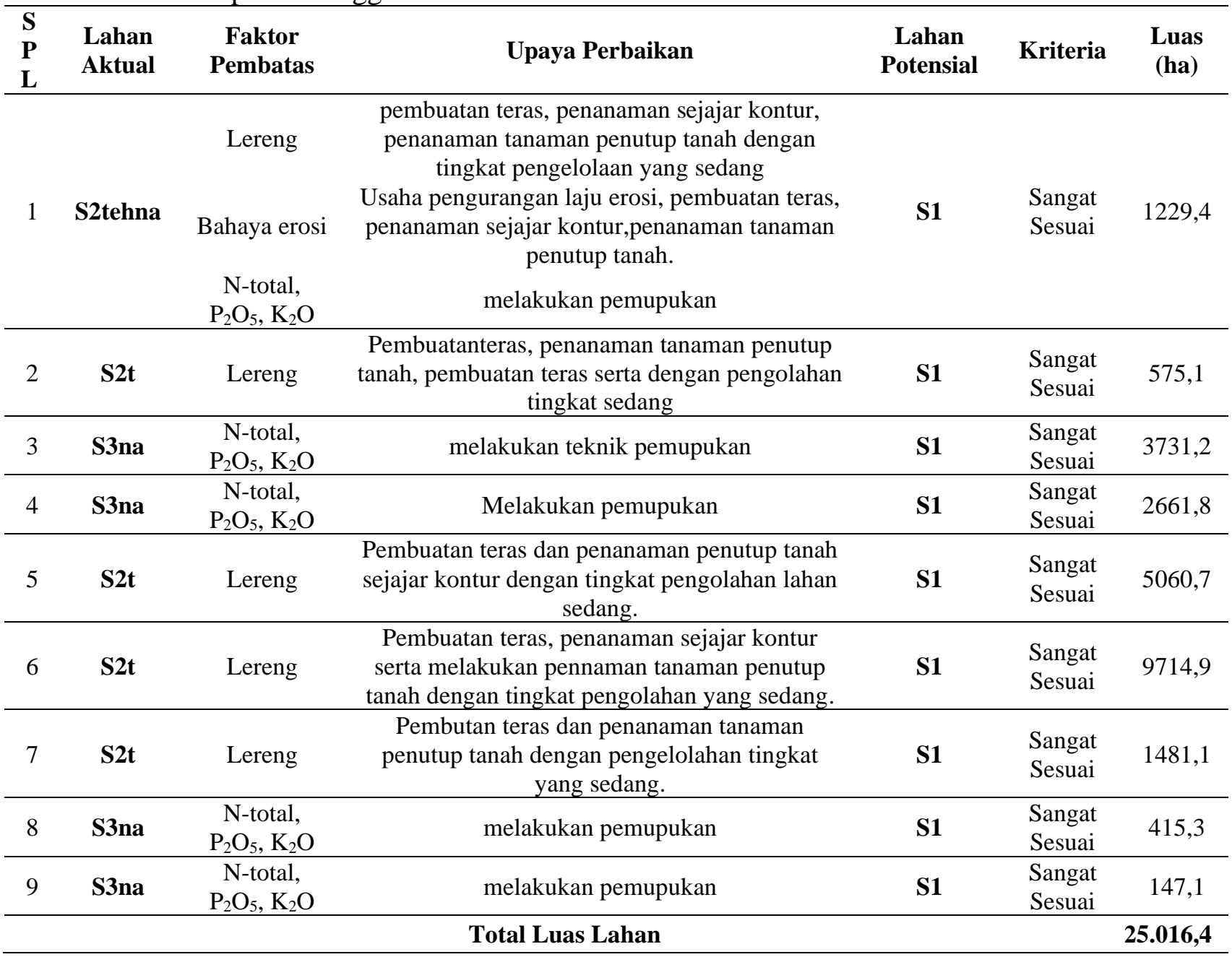

Keterangan $: \mathrm{t}=$ topografi; $\mathrm{eh}=$ bahaya erosi; $\mathrm{na}=$ hara tersedia

\section{Arahan Alokasi Lahan untuk Pengembangan Padi Lokal Ranta dan Habo Kecamatan Batui, Banggai}

Arahan pengembangan komoditi tanaman padi lokal ranta dan habo dapat dibudidayakan di suluruh wilayah Kecamatan Batui. Area yang dianggap berpotensi untuk dilakukan pengembangan komoditi tanaman padi ranta dan habo,dapat dilihat pada peta lahan yang tergolong potensial. Selanjutnya hasil dari kesesuaian lahan yang diperoleh disjaikan dalam bentuk peta potensial untuk padi ranta dan habo (Gambar 1.) 


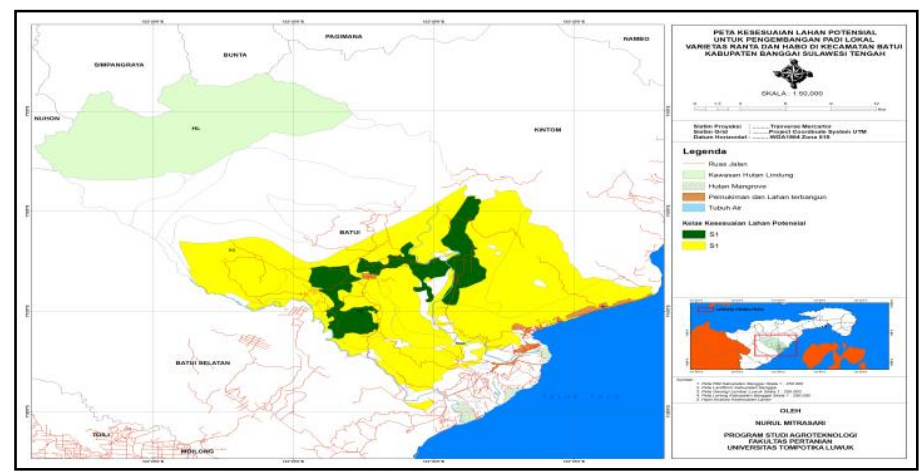

Gambar 1. Peta Kesesuaian Lahan Untuk Padi Ranta dan Habo Kecamatan batui

Dari hasil penggabungan beberapa peta, seperti peta penggunaan lahan, peta tanah dan peta pola ruang dalam rencana pembangunan Kabupaten Banggai, wilayah penelitian yang direkomendasikan mencakup perladangan, kebun campuran, alang alang, hutan rakyat dan konservasi serta area penggunaan lain (Katili, 2021). Artinya dalam pengembangan tanaman padi ranta dan habo di Kecamatan Batui mempunyai prospek yang cerah pada wilayah satuan peta lahan 1 sampai 9, sehingga layak dikembangkan untuk komoditi tersebut karena keseuaian lahannya sangat sesuai/ cocok. Dan apabila terdapat area yang mempunyai KKL dan nilai yang relatif mirip maka akan dipertimbangkan kembali berdasarkan kebijakan prioritas pengembangan komoditas daerah (Setianto and Susilowati, 2014).

\section{KESIMPULAN}

Hasil penelitian diperoleh kelas kesesuaian lahan tanaman padi lokal Ranta dan Habo maka dapat disimpulkan sebagai berikut : Kelas kesesuaian lahan aktual Kecamatan Batui yaitu satuan peta lahan 1, 2,56 dan 7 diperoleh kesesuaian lahan S2 (cukup sesuai) dan untuk Satuan peta lahan 3, 4, 8 dan 9 diperoleh hasil keseuaian lahan aktual yaitu S3 (marginal). Setelah dilakukan upaya perbaikan sesuai faktor pembatas dilokasi penelitian, sehinggahnya diperoleh keseuaian lahan potensial secara keseluruhan yakni Sangat sesuai (S1) dengan luas 25.016,4 ha. Selanjtnya alokasi lahan komoditas tanaman padi lokal ranta dan habo dapat dikembangkan secara menyeluruh diwilayah Kecamatan Batui.

\section{DAFTAR PUSTAKA}

Amir (2018) Pengkajian Paket Teknologi Mendukung Pelaksanaan IP 200 Jagung di Lahan Kering Sulawesi Selatan. Journal of Science and Technology. 7 (3) : $304-315$

Ardianto K. Dan Al Iksan A. (2017). Pengukuran Dan Pendugaan Erosi Pada Lahan Perkebunan Kelapa Sawit Dengan Kemiringan Berbeda. Jurnal Online Mahasiswa (JOM) Riau 4 (1): 1-15

Atmojo YK, Irwan SNR., dan Rogomulyo R. (2018). Pemilihan Alternatif Pohon Buah Untuk Penghijauan Berdasar Karakteristik Tanaman Dan Kesesuaian Lahan Di Area Perkantoran Pemda Bantul, Manding, Yogyakarta. Jurnal Vegetalika 7 (4); 74-88

Da Costa A., Mononimbar W. Dan takumansang E.D. (2019) Analisis Kesesuaian Lahan Permukiman 
Kabupaten Sorong. Jurnal Spasial Perencanaan Wilayah dan Kota 6 (3): 692-702

Dumipto PK,. Rayes ML,. dan Cristanti A (2019). Evaluasi Kesesuaian Lahan Untuk Tanaman Tebu Pada Lahan Karst Formasi Wonosari (TMWL) Kecamatan Gedangan Kabupaten Malang. Jurnal Tanah dan Sumberdaya Lahan 6 (2): 1361-1374

FAO., (1976). Framework for Land evaluation. Soil Resources Menagemen and Conservation Division. FAO Soil Bulletin no. 32. Rome.

Idjudin A., (2011). The Role of Land Conservation in Plantation Management. Jurnal Sumberdaya Lahan. 5 (2); 103-116

Juradi, M.A., Basrum, Syamsyah Gafur dan I Ketut Suwitra. 2015. Kajian Penerapan Varietas Unggul Baru Padi Sawah Irigasi Di Kabupaten Donggala Provinsi Sulawesi Tengah. hlm. 1029-1037. Dalam : Satoto, I. A. Rumanti, U. Susanto, A. Hairmansis, P. Sasmita (eds). Prosiding Seminar Nasional 2014. Buku 2. Sukamandi: Balai Besar Penelitian Tanaman Padi.

Katili H., (2020). Food Crop Land Use Planning in Banggai Regency. Jurnal Pertanian Tropik. 7(1); 12-24.

Khiddir, S. M. 1986. A statistical approach in the use of parametric systems applied to FAO framework for land evaluation. Dissertation. State University of Ghent. Belgium.

Malik A, (2017) Prospek Pengembangan Padi Gogo: Perspektif Kebijakan Dan Implementasi Di Lapangan. Jakarta. IAARD Press. $137 \mathrm{hlm}$

Margolang RD., Jamilah, dan Sembiring M. (2015). Karakteristik Beberapa Sifat Fisik, Kimia dan Biologi Tanah Pada Sistem Pertanian Organik.
Junal Online Agroekoteaknologi. 3 (2); 717-723

Muliyanto R., Sataral M., Yatim H., dan Katili H.A. (2020). Kelas Kesesuaian Lahan Untuk Pengembangan Tanaman Vanili Di Kecamatan Balantak Kabupaten Banggai. Jurnal Pertanian Cemara. 17 (2): 66-74

Murdaningsih dan Nurdiana N. (2009). Kajian Potensi Pengembangan Agrowisata Kawasan Gunung Salak Endah. Jurnal Buana Sains. 9 (1); $31-45$

Nainggolan, H. L., Ginting, A. dan Aritonang, J. (2015) Pengaruh Faktor Fisik dan Sosial Perencanaan Pertanian untuk Meningkatkan Pendapatan Masyarakat dan Pengembangan Wilayah di Humbang Hasundutan. Jurnal Penelitian Pertanian. 3 (1):11-25

Nganji M.U., Simanjuntak B.H. dan Suprihati (2018). Evaluasi Kesesuaian Lahan Komoditas Pangan Utama di Kecamatan Umbu Ratu Nggay Barat Kabupaten Sumba Tengah. Jurnal Agritech. 38 (2); 172-177

Nurdin (2011) Development and Rainfed Paddy Soils Potency Derived From Lacustrine Material in Paguyaman, Gorontalo. Journal of Tropical Soils 16 (3): 267-278

Rayes, M.L., (2007). Metode Inventarisasi Sumber Daya Lahan. Yogyakarta. Andi. $298 \mathrm{hlm}$

Ritung S., Nugroho K., Mulyani A. dan Suryani E. (2011). Petunjuk Teknis Evaluasi Lahan Untuk Komoditas Pertanian (Edisi Revisi). Balai Besar Penelitian dan Pengembangan Sumberdaya Lahan Pertanian, Badan Penelitian dan Pengembangan Pertanian, Bogor. 
Rosmaiti, Saputra I., Dan Yusnawati (2019). Evaluasi Kesesuaian Lahan Untuk Pengembangan Tanaman Jeruk (Citrus, Sp) Di Desa Jambo Labu Kecamatan Birem Bayeun Kabupaten Aceh Timur. Jurnal Ilmiah Pertanian 16 (1); 64-73

Safitri A. (2018) Morfologi Padi Gogo Lokal (Oryza Sativa L.) Asal Kecamatan Bangko Kabupaten Rokan Hilir Pada Fase Vegetatif. Skripsi, Universitas Islam Negeri Sultan Syarif Kasim Riau.

Salwati dan Saidi B.B. (2008) Landform Classification which Alighted from Digital Elevation Models: Case in Citarum Watershed, Cilalawi Sub Watershed, West Java. Jurnal Of Tropical Soil. 13 (12): 139-144

Sarwanto, Samudin S, Andi E (2018) Karakterisasi Beberapa Kultivar Padi Gogo Lokal. Jurnal Ilmu Pertanian Agrotekbis 6 (2):274-284.

Setianto, P. \& Susilowati, I. (2014). Komoditas Perkebunan Unggulan yang Berbasis Pada Pengembangan Wilayah Kecamatan di Kabupaten Banjarnegara Provinsi Jawa Tengah. Jurnal Wilayah dan Lingkungan. 2 (2): 143-156

Siregar KR., Nasution Z. dan Sitorus B. (2019). The evaluation of land suitability to Upland rice (Oryza sativa L.) and Onion (Allium ascalonicum L.) in Kualuh Hulu Subdistrict Of North Labuhanbatu District. Jurnal Agroekoteknologi FP USU. 7 (1): 8-19

Siswanto, (2006). Evaluasi Sumber Daya Lahan. Surabaya : UPN Press. 120 hlm

Suardi D. (2002) Perakaran padi dalam hubungannya dengan toleransi tanaman terhadap kekeringan dan hasil. Jurnal Litbang Pertanian 21(3): 100-108

Suryawan I.B., Adi IG.P.R dan Dibia IN. (2020). Evaluasi Kesesuaian Lahan Untuk Beberapa Tanaman Pangan Dan Perkebunan Di Kecamatan Burau Kabupaten Luwu Timur Sulawesi Selatan. Jurnal Agroteknologi Tropika 9 (1): 62-75

Susanto U, Samsul A., Wage R. R., dan R. H. Wening (2020). Kesesuaian Galur Padi pada Lahan Sawah Tadah Hujan. Jurnal Penelitian Pertanian Tanaman Pangan 4 (2): 119-124

Syah MW \& Hariyanto T. (2013). Klasifikasi Kemiringan Lereng Dengan Menggunakan Pengembangan Sisten Informasi Geografis Sebagai Evaluasi Kesesuaian Lahan Pemukiman Berdasarkan Undang-Undang Tata Ruang dan Metode Fuzzy. Jurnal Teknik Pomits. 10(10): 1-6

Sys, C. E. Van Ranst. J. Debaveye dan F. Beernaert. (1991). Land evaluation part I: principles in land evaluation and crop calculations. Part II: methods in land evaluation. BrusselBelgium: Agricultural publication no. 7

Wati Y., Alibasyah R., dan Manfarizah (2014). Pengaruh Lereng dan Pupuk Organik Terhadap Aliran Permukaan, Erosi dan Hasil Kentang di Kecamatan Atu Lintang Kabupaten Aceh Tengah. Jurnal Manajemen Sumberdaya Lahan. 3 (6) : 496-505

Yanti, D. Arlius, F. dan Nurmansyah, W. (2015) Analisis Kesesuaian Lahan Untuk Tanaman Perkebunan Di Kecamatan Bungus Teluk Kabung Kota Padang. Jurnal Teknologi Pertanian Andalas. 19 (1): 15-26. 